\title{
SUMMARY OF SCAN SITES 2 AND 3
}

\author{
G. W. Moore, U. S. Geological Survey, La Jolla, California \\ and \\ G. F. Sharman, Scripps Institution of Oceanography, La Jolla, California
}

\section{OBJECTIVES OF DRILL HOLES}

Sites 2 and 3, located 22 kilometers apart, are discussed together here. Site 2 is at latitude $39^{\circ} 30^{\prime} \mathrm{N}$, longitude $127^{\circ} 30^{\prime} \mathrm{W}$; and, Site 3 is at latitude $39^{\circ} 30^{\prime} \mathrm{N}$, longitude $127^{\circ} 15^{\prime} \mathrm{W}$. The water depth at Site 2 is 4260 meters, and at Site 3 it is 4300 meters; the sediment thickness at both sites is approximately 400 meters. The sites are located between the Pioneer and Mendocino Transform Faults, near the toe of Delgada Fan. Site 2 lies on a characteristic positive magnetic anomaly, and Site 3 on an adjacent negative anomaly. The positive anomaly at Site 2 has been correlated by Vacquier and others (1961) with an anomaly at Site 6, which is offset to the west, north of the Mendocino Transform Fault. The objectives at these holes were to investigate differences in the basement between adjacent positive and negative magnetic anomalies, to check the correlation between Sites 2 and 6 , and to sample oceanic sediment that is relatively close to the North American continent.

\section{SURVEY METHODS}

The survey of these sites was made from the Argo between March 10-12, 1969. Navigation was by Loran A, with a fix precision of approximately 2 kilometers. Magnetic-intensity traverses and acoustic-reflection profiles at $12,3.5$ and $0.1 \mathrm{kHz}$ were run on a grid 75 kilometers square, with tracks about 20 kilometers apart. Near Site 2, a piston core was taken and the heat flow was determined. On the acoustic-reflection profiles reproduced here, a 10-second sweep was used, and the distance between hour marks was approximately 20 kilometers.

\section{NATURE OF SITES}

The bottom topography is smooth and partially masks on the basement former hills of presumed volcanic origin. Because of the basement irregularities, sediment thickness ranges from about 350 to 450 meters. The sea-floor sediment at Site 2 grades from soft grayishbrown clay at the top to brittle olive-gray clay at a depth of 10 meters. Stratification as revealed by the acoustic-reflection profiles is more apparent at Site 3 to the east nearer the continent than at Site 2. The entire top 10 meters at Site 2 contain Pleistocene microfossils. The heat flow is about average at $1.3 \mu \mathrm{cal} / \mathrm{cm}^{2}$ sec.

\section{MICROPALEONTOLOGY}

David Bukry

U. S. Geological Survey, La Jolla

\section{General Comments}

Samples taken at 1.5 -meter intervals from the piston cores, recovered during the preliminary surveys of the proposed Deep Sea Drilling Project sites in the northeast Pacific, were examined for calcareous nannofossils. The identified assemblages of nannofossils indicate that Pliocene sediment containing abundant discoasters is present in the upper 10 meters at only one place, Site 6 . Elsewhere, only Pleistocene assemblages are present in the upper 10 meters. The abundant, widely distributed, Holocene nannofossil, Emiliania huxleyi (Lohmann) is not represented in any of the samples examined.

Diatoms are common only in surface samples (0 to 1 centimeter) at Sites 1,2 and 4 . Foraminifera are sparsely present in several samples from Sites 1, 2, 4, 5 and 6.

\section{SCAN-2-P}

Core length: 9.9 meters. Pleistocene calcareous nannofossil assemblages are present throughout this core. Characteristic species include: Coecolithus pelagicus (Wallich), Cyclococcolithus leptoporus Murray and Blackman var. C of McIntyre, Bé and Preikstas, and Gephyrocapsa oceanica Kamptner.

\section{SCAN-3-P}

No core was taken. 


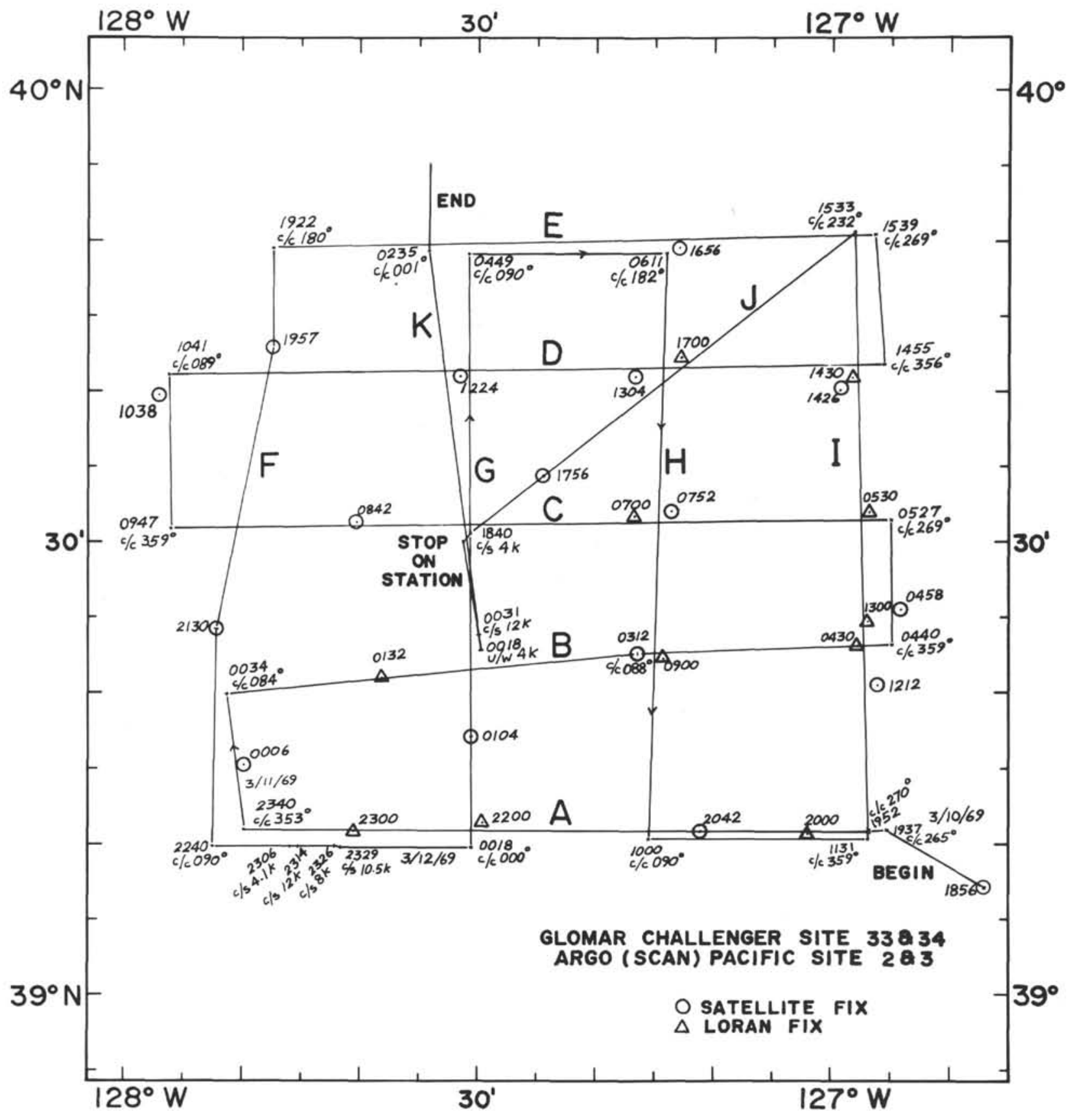




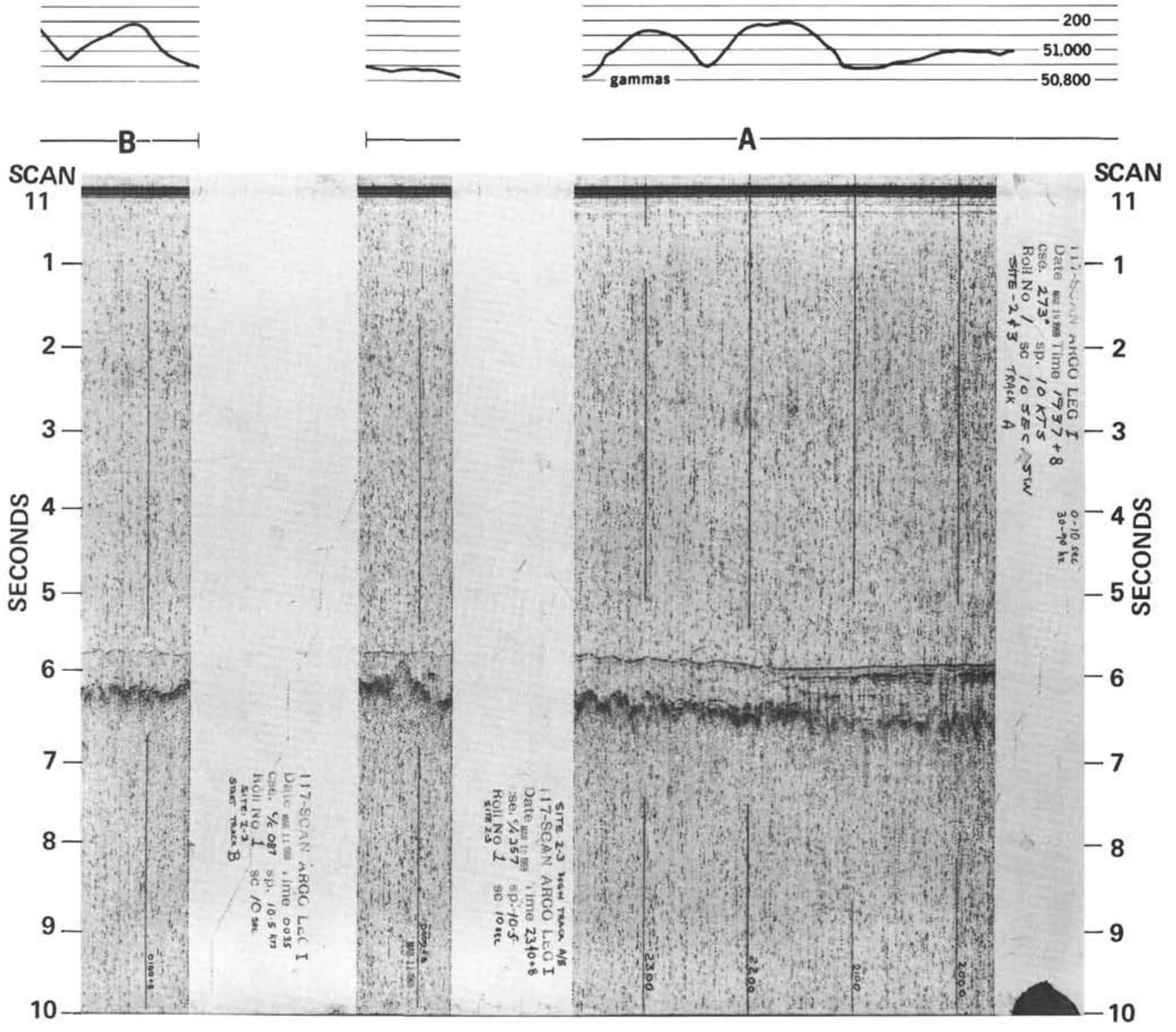

SCAN Survey, Sites 2 and 3, Tracks A and B. 


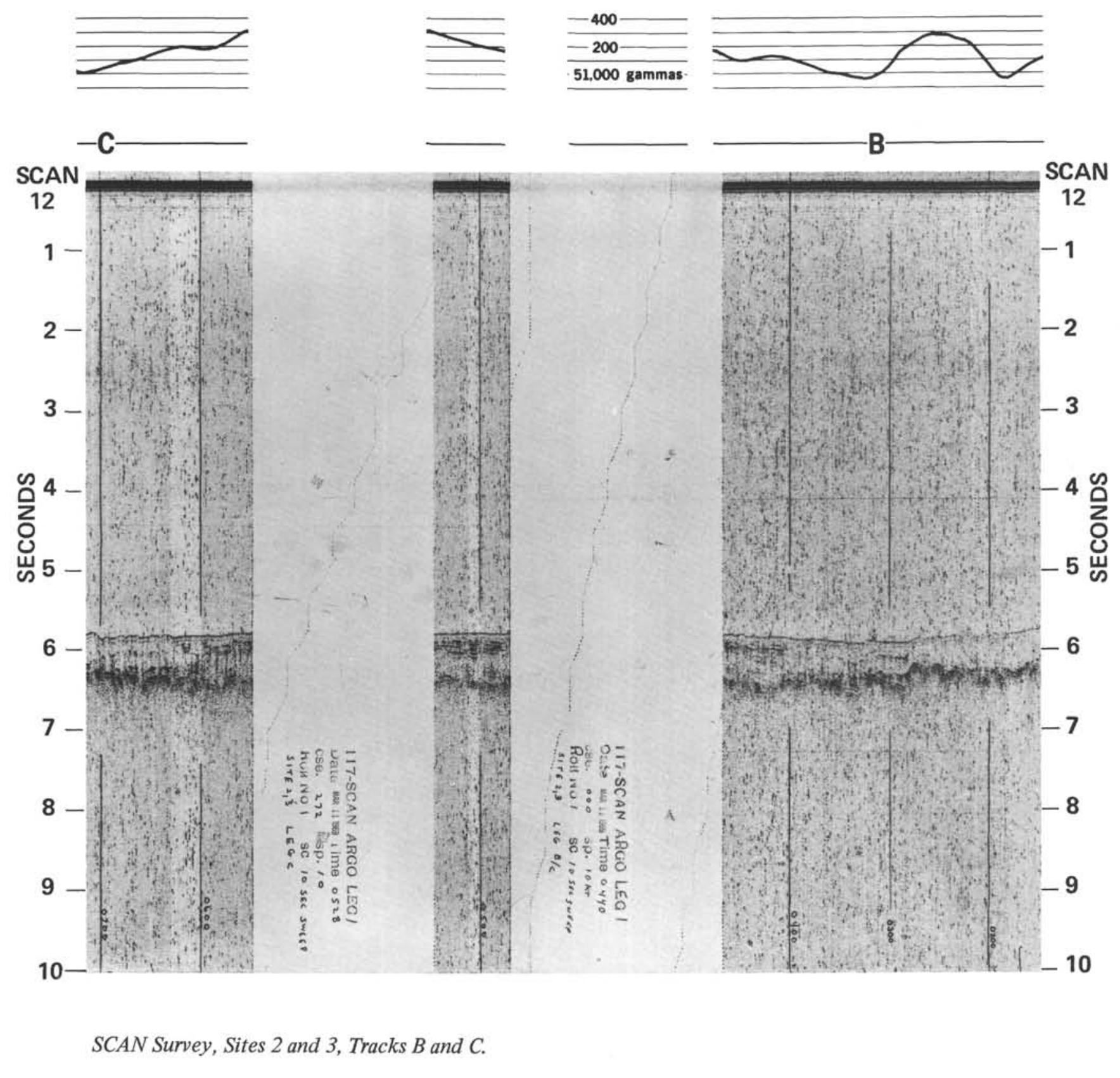




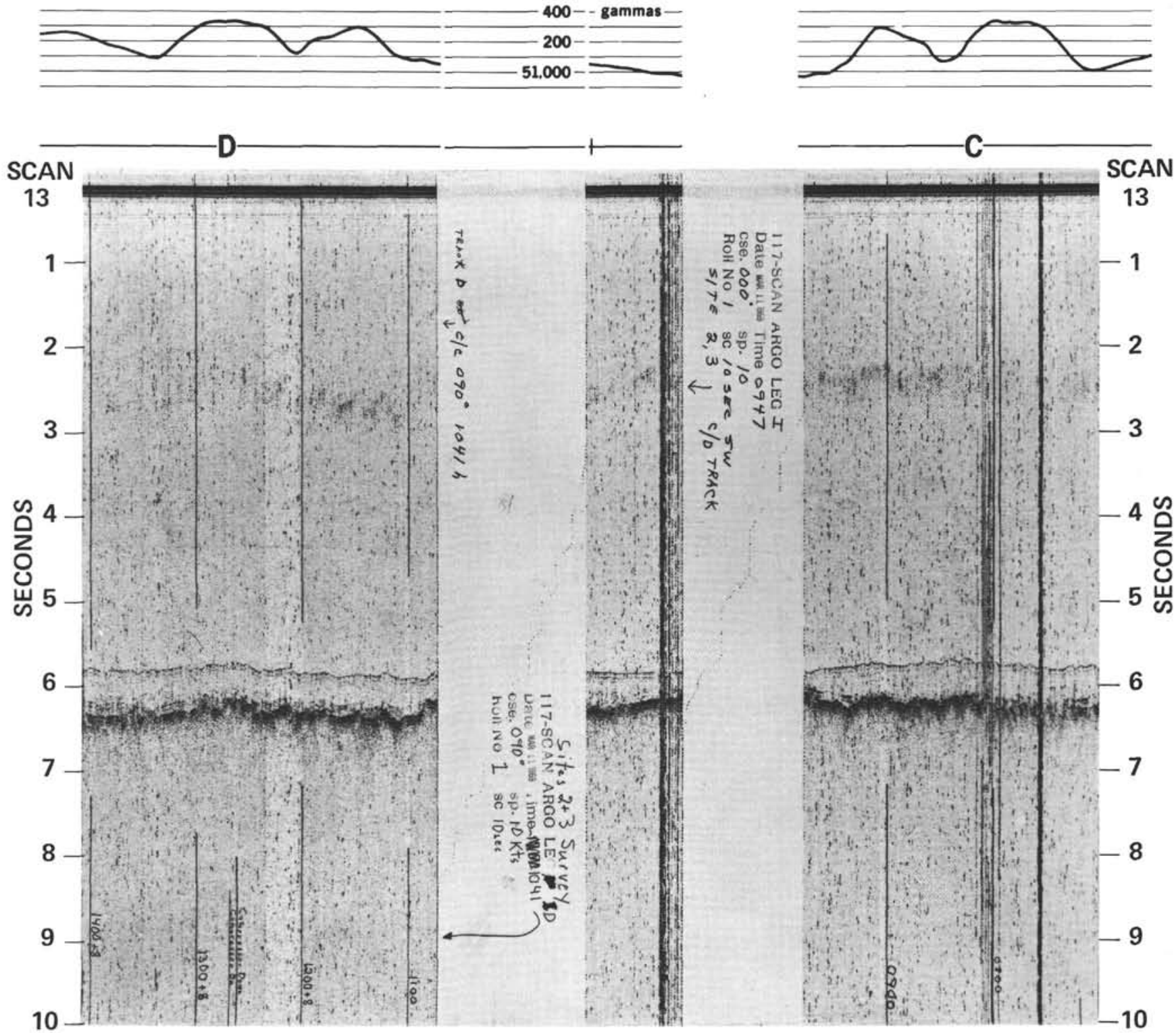

SCAN Survey, Sites 2 and 3, Tracks $C$ and D. 

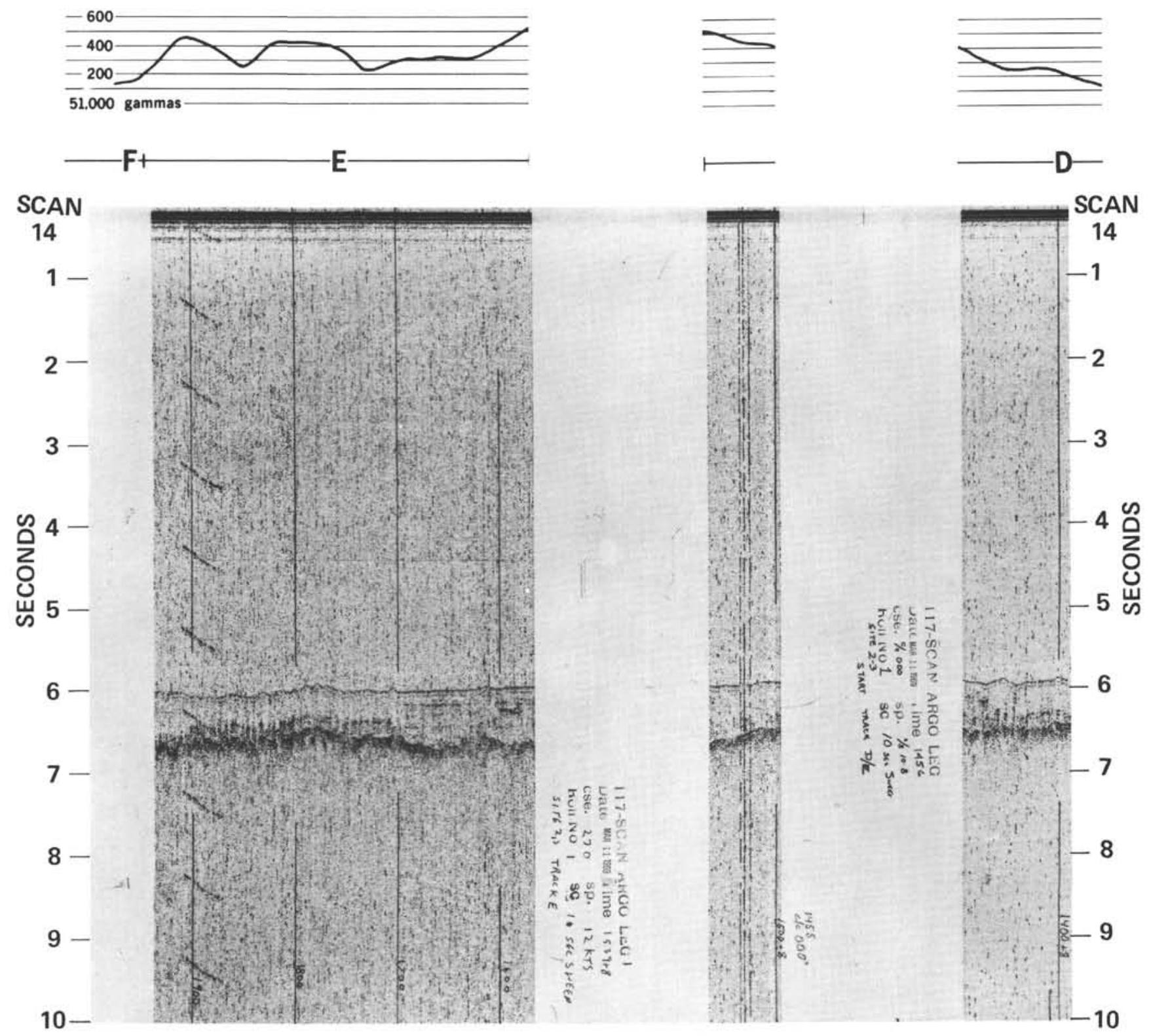

SCAN Survey, Sites 2 and 3, Tracks D, E and F. 


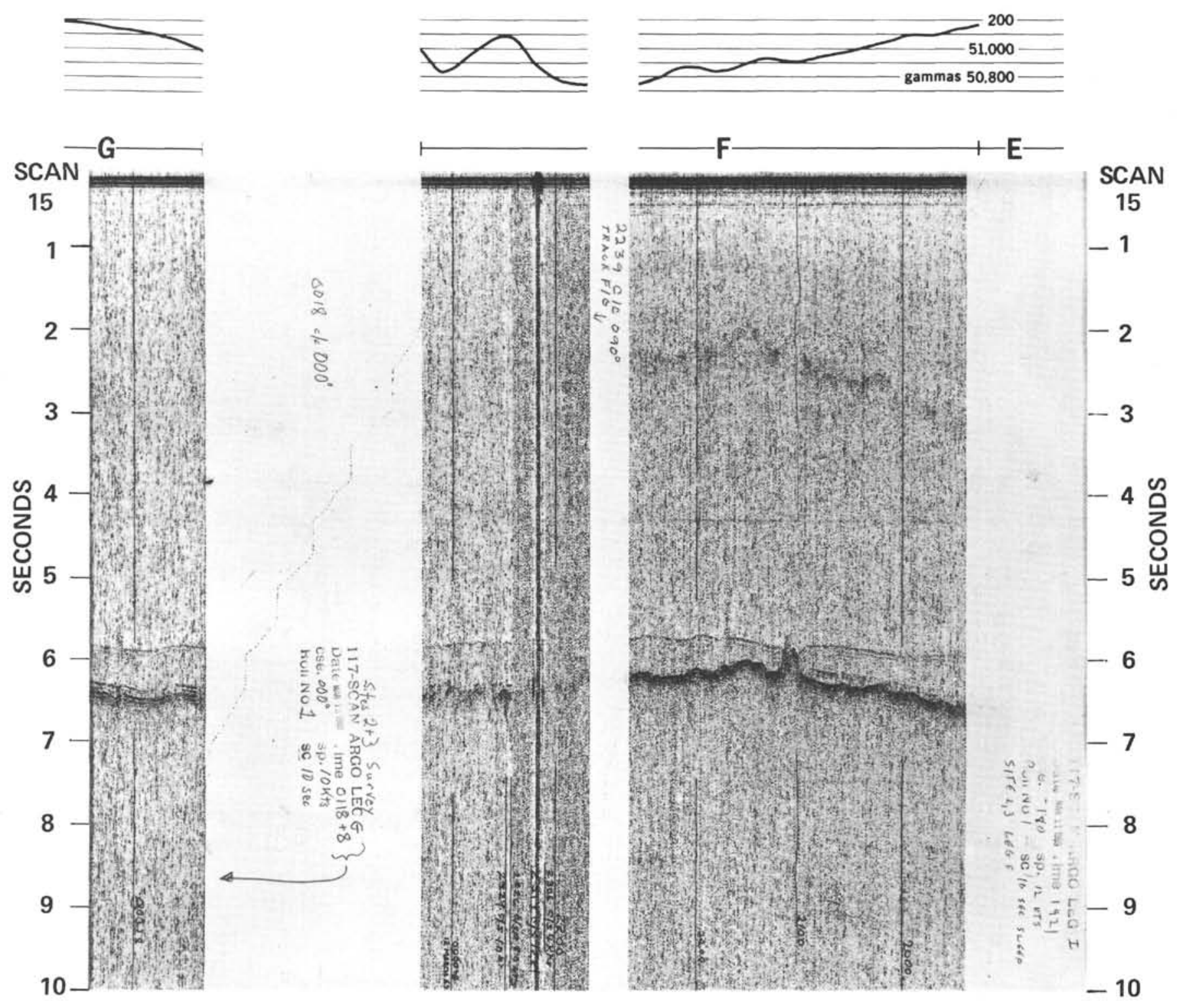

SCAN Survey, Sites 2 and 3, Tracks E, F and $G$. 

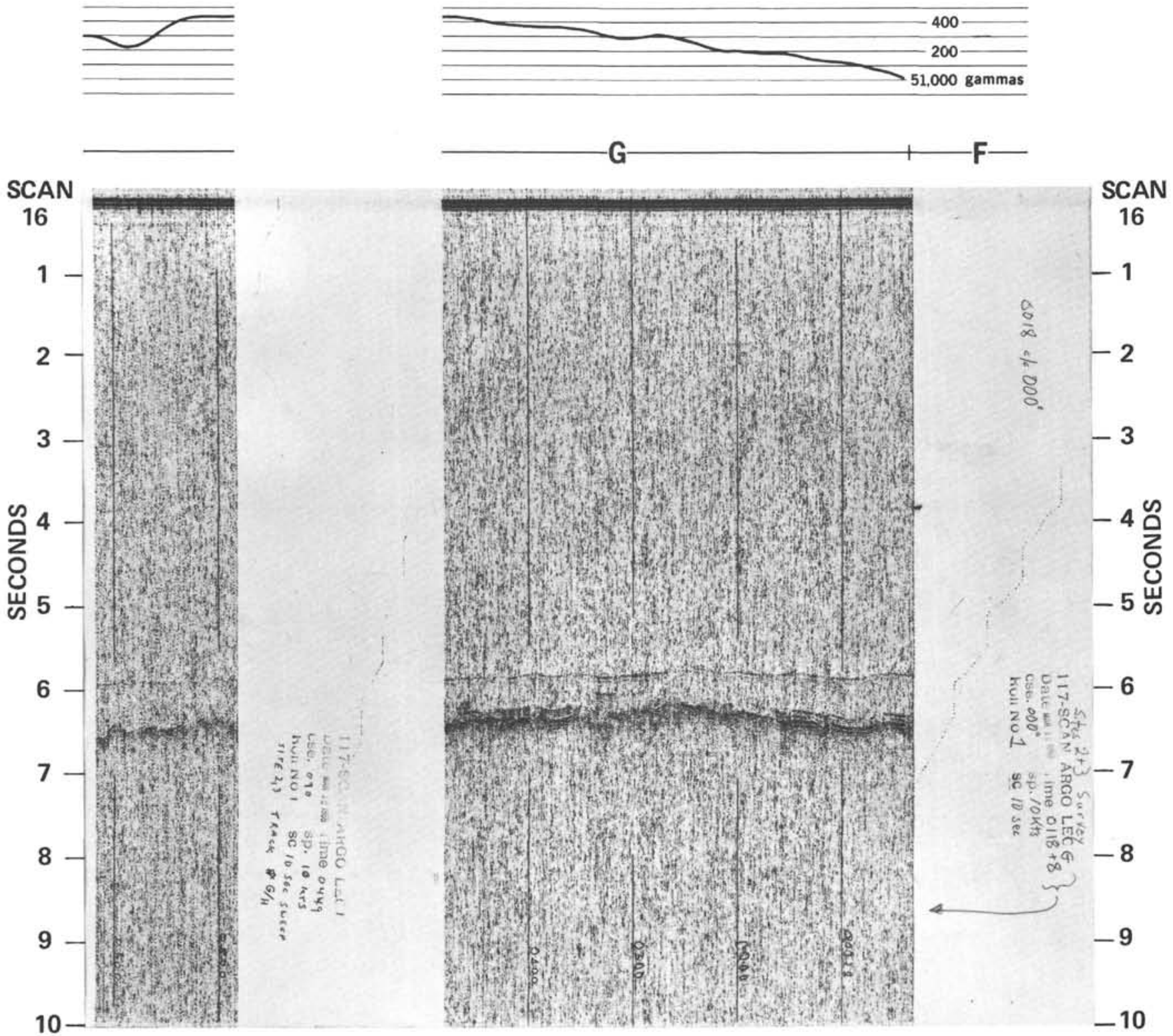

SCAN Survey, Sites 2 and 3, Tracks $F$ and $G$. 


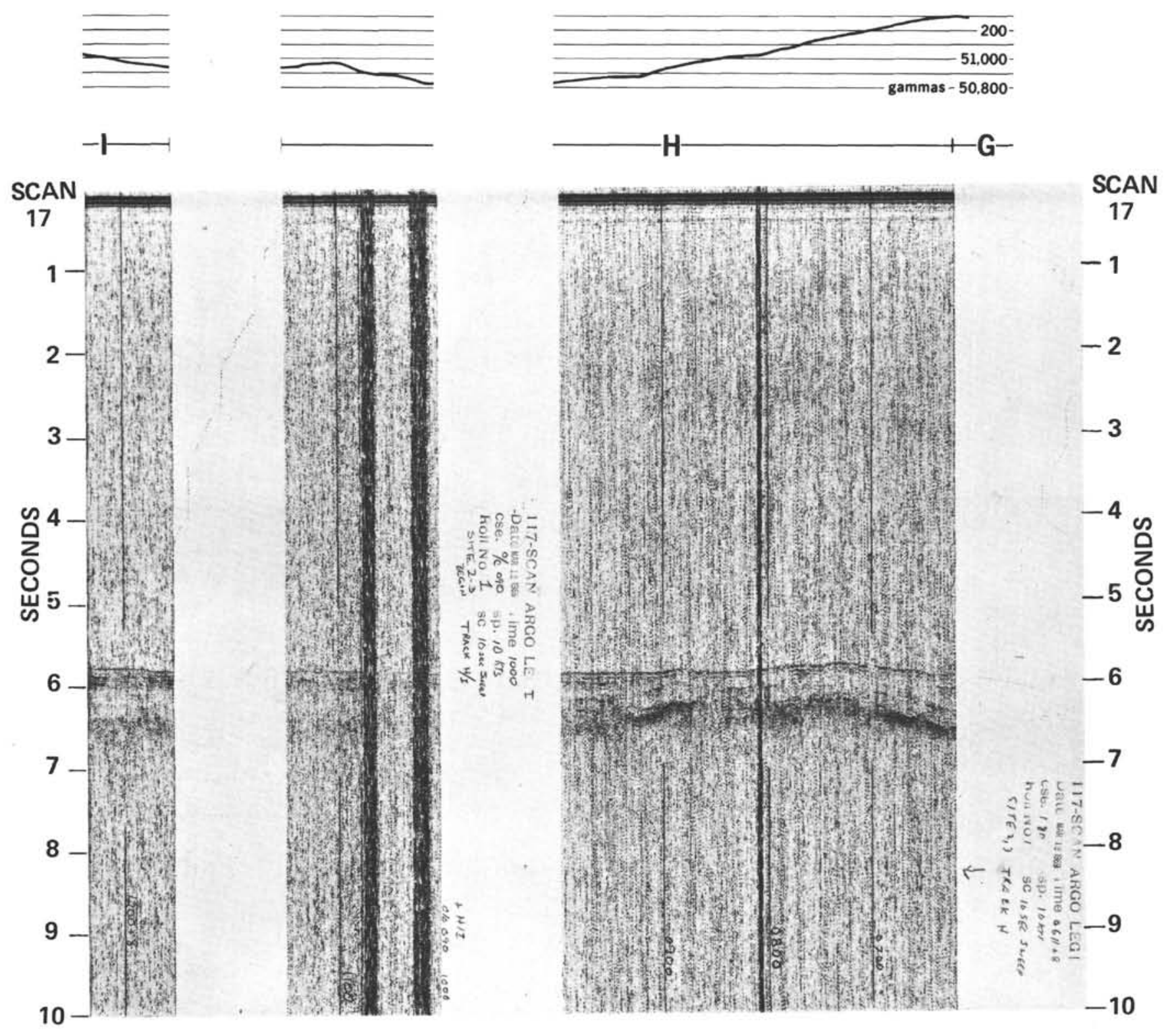

SCAN Survey, Sites 2 and 3, Tracks $G, H$ and $I$. 

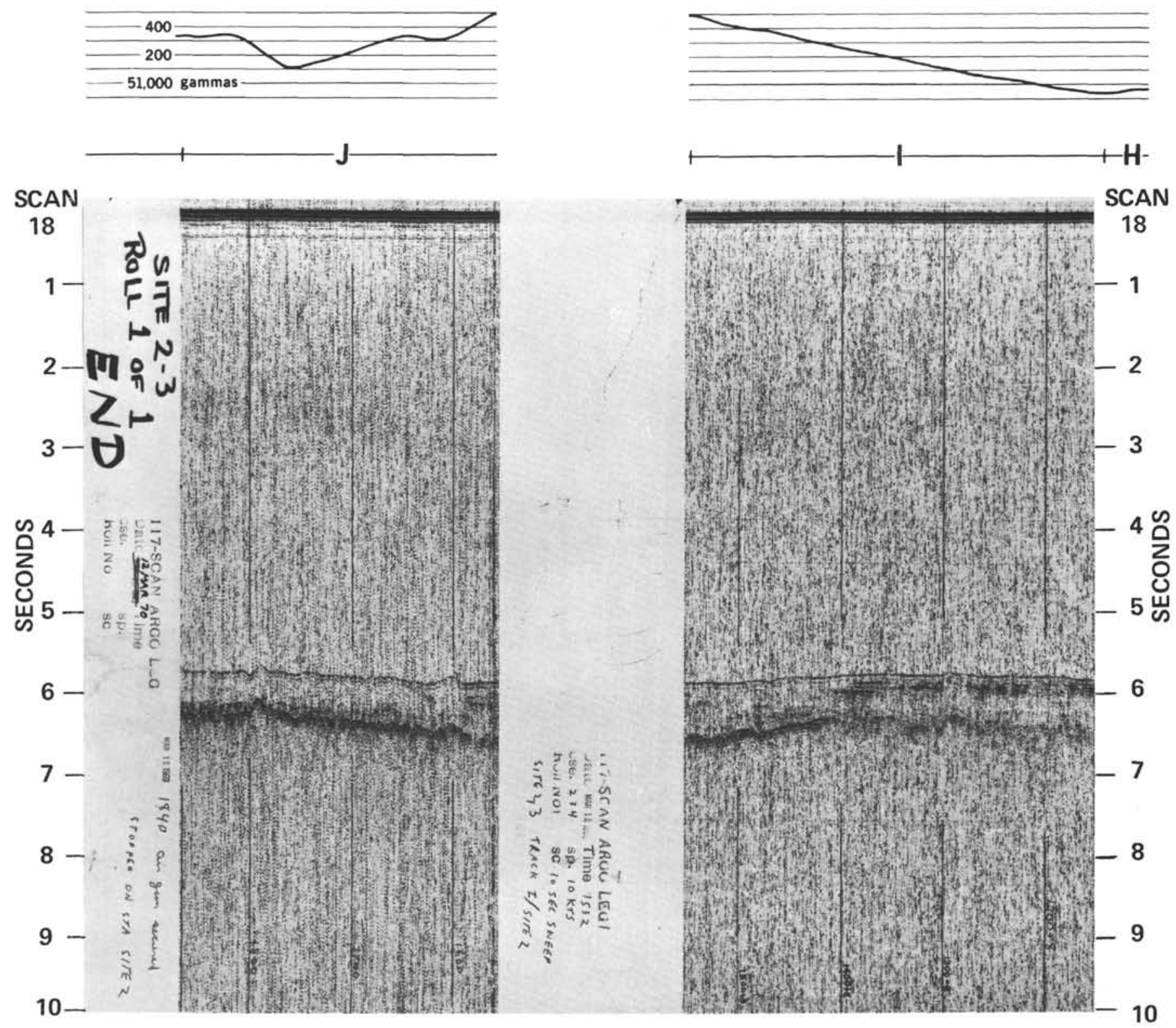

SCAN Survey, Sites 2 and 3, Tracks $H, I$ and $J$.

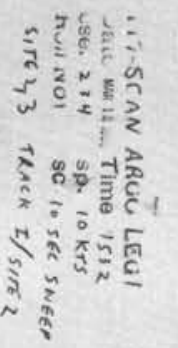




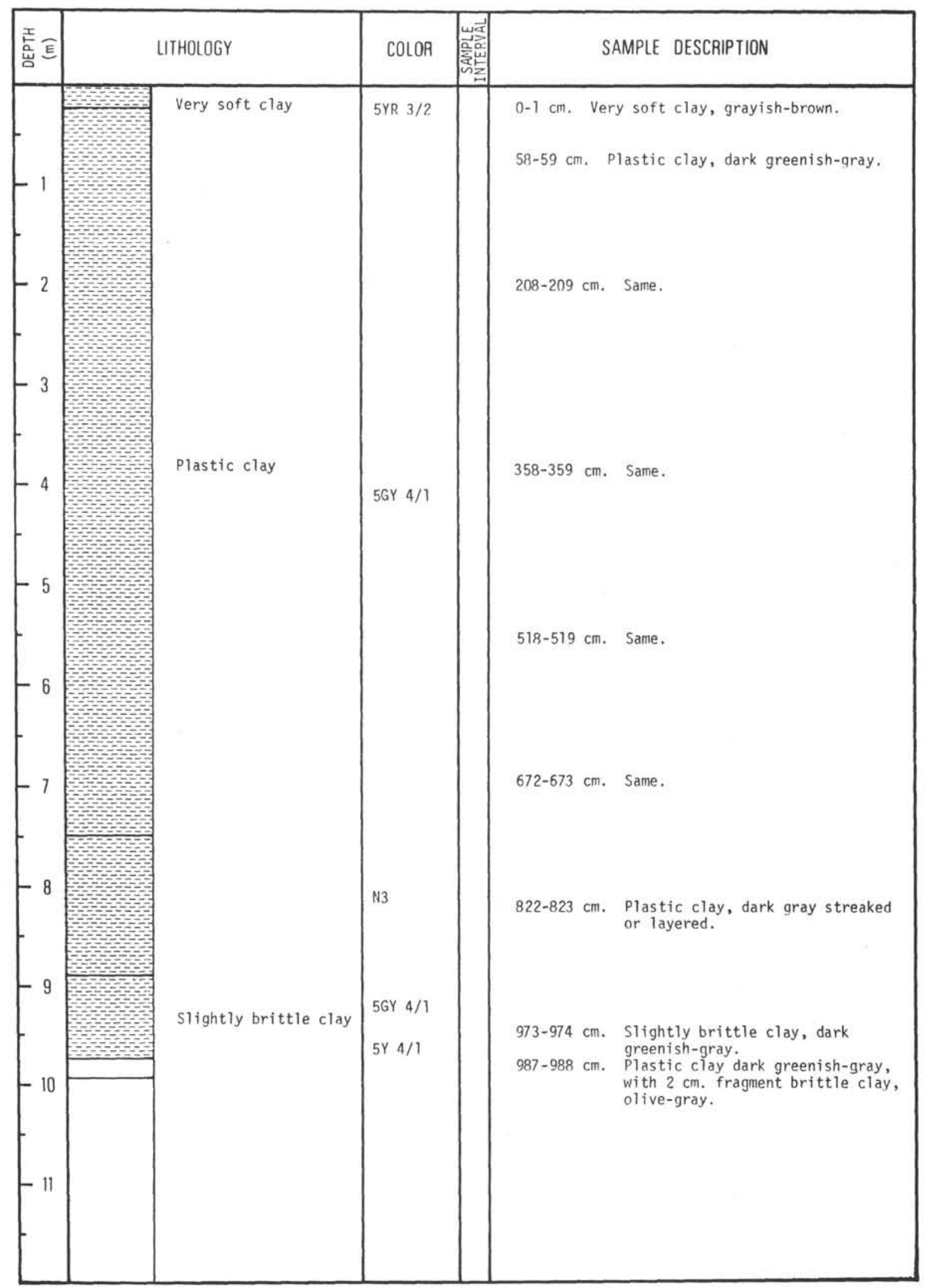

Summary of Piston Core 2. 